\title{
Intracellular calcium and hormone release from nerve endings of the neurohypophysis in the presence of opioid agonists and antagonists
}

\author{
Govindan Dayanithi $^{1 *}$, Edward L. Stuenkel ${ }^{2}$, and Jean J. Nordmann ${ }^{1}$ \\ ${ }^{1}$ Centre de Neurochimie, 5, Rue Blaise Pascal, F-67084 Strasbourg Cedex, France \\ ${ }^{2}$ Department of Physiology, Medical School, University of Michigan, Ann Arbor, MI 48109, USA
}

Received August 12, 1991 / Accepted March 10, 1992

\begin{abstract}
Summary. Rat neural lobes and isolated nerve terminals from the neurohypophysis were stimulated in the presence of different opioid agonists and antagonists. The secretion of arginine vasopressin and oxytocin and rise in cytoplasmic calcium induced by depolarization were analyzed by radioimmunoassay and the fluorescent probe fura-2, respectively. The kappa-agonists dynorphin $A_{(1-13)}$ and dynorphin $A_{(1-8)}$ did not affect electrically evoked release of vasopressin, although oxytocin release was slightly reduced. U-50 488 , a relatively specific kappa-receptor agonist, had no effect on the amount of vasopressin or oxytocin secreted, although it significantly reduced $\mathrm{K}^{+}$-evoked changes in $\left[\mathrm{Ca}^{2+}\right]_{\mathrm{i}}$ in isolated nerve endings. Two kappa-receptor antagonists, MR 2266 and diprenorphin, alone had no effect on vasopressin and oxytocin secretion from isolated nerve endings depolarized with potassium. Opioid agonists less selective for the kappa receptors, etorphin and ethylketocyclazocin, were found to inhibit the release of both vasopressin and oxytocin significantly. Naloxone, a nonselective opiate receptor antagonist, alone had no effect on vasopressin release but potentiated the electrically evoked release of oxytocin. Naloxone also could overcome the inhibitory effect of etorphin on oxytocin and vasopressin release observed after electrical stimulation of the neural lobe. A number of inconsistencies therefore exist between the effects of opioid agonists and antagonists on neuropeptide release and on the evoked changes in $\left[\mathrm{Ca}^{2+}\right]_{\mathrm{i}}$. In view of these inconsistencies and the high concentrations of opioid agonists and antagonists necessary to modify release, we conclude that it is doubtful that opioid molecules have a physiological role in controlling neurohypophysial secretion.
\end{abstract}

Key words: Opioid peptides - Neurohypophysis - Nerve endings - Vasopressin - Oxytocin - Calcium - Release - Rat

* Present address: G. Dayanithi, Laboratoire de Neurobiologie Endocrinologique, URA 1197 CNRS, Université Montpellier-II, F-34095 Montpellier Cedex 5, France

Correspondence to: E.L. Stuenkel

\section{Introduction}

The role of opiates in the release of neurohormones from the hypothalamo-neurohypophysial system has been extensively studied over the last decade. However, the published data are contradictory. For example, Iversen et al. (1980) have reported that Leu-enkephalin inhibits the release of vasopressin (AVP) from the neural lobe. Although this has been confirmed (Lightman et al. 1982; Al-Zein et al. 1984), other studies have failed to reproduce these results (Denker et al. 1982; Nordmann et al. 1986). In addition, the effects of the $\delta$-agonist Leuenkephalin are puzzling, as it has been shown recently that the neural lobe contains predominantly opioid kappa receptors (Pesce et al. 1987). Studies on the effects of naloxone, which binds preferentially (but not only) to opioid $\mu$-receptors, have also resulted in contradictory reports. Whereas some investigations have shown no effect on electrically induced release of vasopressin (Bicknell and Leng 1982; Nordmann et al. 1986) or oxytocin (OT) (Pitzel and Konig 1984), other reports have indicated that naloxone either greatly potentiates OT release (Bicknell and Leng 1982), and to a lesser extent that of AVP (Zhao et al. 1988a), or that it decreases evoked AVP secretion (Knepel and Meyer 1983). Furthermore, DAGO, a $\mu$-receptor agonist, was found to partially inhibit both AVP and OT release (Zhao et al. 1988a). Most recently, it has been shown that the kappa-type opioid receptors are found not only on pituicytes, as first reported (Lightman et al. 1983), but also on the neurosecretory nerve endings (Gerstberger and Barden 1986; Pesce et al. 1987; Falke and Martin 1988). Moreover, kappa-receptor agonists have been shown to inhibit the release of AVP and OT from electrically stimulated neural lobes (Zhao et al. 1988a) and from potassiumdepolarized nerve endings (Zhao et al. 1988b). In the present study, we have continued our previous investigations (Nordmann et al. 1986) on the role of opioid molecules in regulating exocytosis in the rat neural lobe. The experiments have been performed on both intact neurohypophyses and on preparations of isolated nerve end- 
ings. Here, we report the effects on the release of AVP and OT, together with changes in cytoplasmic-free calcium concentration $\left(\left[\mathrm{Ca}^{2+}\right]_{j}\right)$ to application of various opioid agonists and antagonists.

\section{Material and methods}

\section{Perfusion of neural lobes and isolated neurosecretory nerve endings}

Neurohypophyses were isolated from male rats (Wistar or Sprague Dawley) weighing $220-240 \mathrm{~g}$ and were separated from the pars intermedia. Single neural lobes were impaled on one of a pair of platinum electrodes, which were positioned into a perfusion chamber. The chamber, $30-50 \mu \mathrm{l}$ in volume, was maintained at $37^{\circ} \mathrm{C}$ and perfused during the first $45 \mathrm{~min}$ of incubation at a rate of $25 \mu \mathrm{l} / \mathrm{min}$, which was then increased to $50 \mu \mathrm{l} / \mathrm{min}$, with physiological saline (PS), continuously gassed with $5 \% \mathrm{CO}_{2}$ in $\mathrm{O}_{2}$, containing (mM): $\mathrm{NaCl}, 140 ; \mathrm{KHCO}_{3}$, $5 ; \mathrm{MgCl}_{2}, 1 ; \mathrm{CaCl}_{2}, 2.2$; glucose, 10 ; TRIS-HEPES, 10 ; $\mathrm{pH} 7.1-7.2$ and $0.01 \%$ BSA. Fractions were collected every $4 \mathrm{~min}$ and stored at $-70^{\circ} \mathrm{C}$ before subsequent radioimmunoassay of secreted AVP and OT (for details see Cazalis et al. 1985). Secretion was evoked with either electrical stimulation or with depolarizing concentrations of potassium ( 60 or $100 \mathrm{mM}$ ). Osmotic equivalence was maintained in solutions containing elevated $\mathrm{K}^{+}$by decreasing the $\mathrm{Na}^{+}$concentration accordingly. In some experiments, $\mathrm{Na}^{+}$-free media was used as it induces a much larger $\mathrm{K}^{+}$-evoked hormone release (Dreifuss et al. 1971; Nordmann 1976) and thus was important for studying small differences in neuropeptide release in the presence or absence of opioid molecules. In those experiments, the release was evoked with $\mathrm{Na}^{+}$-free saline containing $100 \mathrm{mM} \mathrm{K}^{+}$and the osmolarity adjusted with choline. In the case of electrically induced depolarization, the neural lobes were stimulated with electrical pulses arranged in 4 bursts, separated by 21 -s silent intervals, which had a pattern of discharge similar to the bursting activity of vasopressin cells in vivo (for details see Cazalis et al. 1985). Each burst contained 348 pulses given at a mean frequency of $13 \mathrm{~Hz}$. This was used instead of constant frequency stimulation, as it is a more appropriate stimulation paradigm. We have stressed elsewhere the importance of the use of bursts of pulses in studies on the release of AVP from isolated neural lobes (Cazalis et al. 1985). For $\mathrm{K}^{+}$-stimulation, neural lobes or isolated nerve endings were depolarized during a period of 8 or $10 \mathrm{~min}$.

Isolated nerve endings were prepared as described previously (Cazalis et al. 1987a). Following isolation, the nerve endings were resuspended in PS (see above) and loaded onto $0.22 \mu \mathrm{m}$ filters (GS, Millipore). The filters were perfused for $45 \mathrm{~min}$ at a flow rate of $25 \mu \mathrm{l} / \mathrm{min}$ which was then increased to $50 \mu \mathrm{l} / \mathrm{min}$. Collection of the perfusate started $90 \mathrm{~min}$ after loading the endings on the filter. Collected fractions were of 4 min duration.

In most of the experiments reported in this paper, we used the $\mathrm{S}_{2} / \mathrm{S}_{1}$ paradigm for analysis of secretion described by Iversen et al. (1980). The neural lobes, or the nerve endings, received two stimulation periods $\left(S_{1}\right.$ and $\mathrm{S}_{2}$ ) separated by a period of $60 \mathrm{~min}$. The amount of hormone release during each stimulation period was calculated by subtracting the amount of hormone released under basal conditions from that observed during, and directly after the stimulus. The effects of opioid agonists or antagonists were tested by adding them $20 \mathrm{~min}$ prior to and during the second stimulation period $\left(\mathrm{S}_{2}\right)$. The effect of different molecules tested was then expressed by the changes in the ratio $S_{2} / S_{1}$ from controls in which no agonists nor antagonists were added.

\section{$\left[\mathrm{Ca}^{2+}\right]_{i}$ measurements in isolated terminals}

Determination of $\left[\mathrm{Ca}^{2+}\right]_{\mathrm{i}}$ in individual nerve endings was performed by dual wavelength microspectrofluorimetry following loading with fura-2/AM. The microspectrofluorimetry equipment and perfusion chamber utilized to monitor $\left[\mathrm{Ca}^{2+}\right]_{\mathrm{i}}$ in individual or small groups of nerve endings was identical to that previously described (Stuenkel 1990). All measurements were performed at $37^{\circ} \mathrm{C}$ in a chamber providing rapid exchange of the superfusing physiological saline. The fluorescence ratio was converted to $\left[\mathrm{Ca}^{2+}\right]_{\mathrm{i}}$ using the equation of Grynkiewicz et al. (1985). Values of $R_{\min }, R_{\max }$ and $F o / F s$ were determined using an external standard calibration technique. $A K_{d}$ value for fura-2 of $224 \mathrm{nM}$ was taken from the literature. Because, according to some authors, AVP-containing nerve endings respond differently to opioids than OTcontaining terminals, we analyzed the effects of drugs on groups of 3-6 nerve endings to avoid misleading results, which could have been obtained from a single nerveending class.

\section{Chemicals}

Naloxone and U-50 488 were a gift from John Bicknell (Babraham, England). Ethylketocyclazocine, etorphin and diprenorphin were kindly given to us by Pierre Giraud (Marseille, France). We are grateful to Dr. Kempf (Strasbourg, France) for giving us MR 2266, which was a gift from Boehringer. Dynorphin $A_{(1-13)}$ or dynorphin $A_{(1-8)}$ was obtained from CRB, Cambridge (England) or Peninsula Laboratories (USA); in some experiments it was diluted in saline containing protease inhibitors at the following concentrations: aprotinin, $0.1 \mathrm{mg} \mathrm{ml}^{-1}$; pepstatin A $10^{-3} \mathrm{M}$; Leupeptin $10^{-3} \mathrm{M}$; TAME $0.1 \mathrm{mg} \mathrm{ml}^{-1}$; chloroquine $10^{-4} \mathrm{M}$; soybean trypsin inhibitor $10^{-2} \mathrm{M}$ and PMSF $10^{-3} \mathrm{M}$.

\section{Results}

\section{Effects of opioid agonists on neurohormone release}

The effects of dynorphin $A_{(1-13)}$ and $U-50488$, opioid kappa-receptor agonists, on electrically evoked release of AVP and OT from intact neural lobes are presented in Figure 1. No significant change in the release of AVP was found upon treatment with dynorphin $A_{(1-13)}$ (Fig. 1a) 

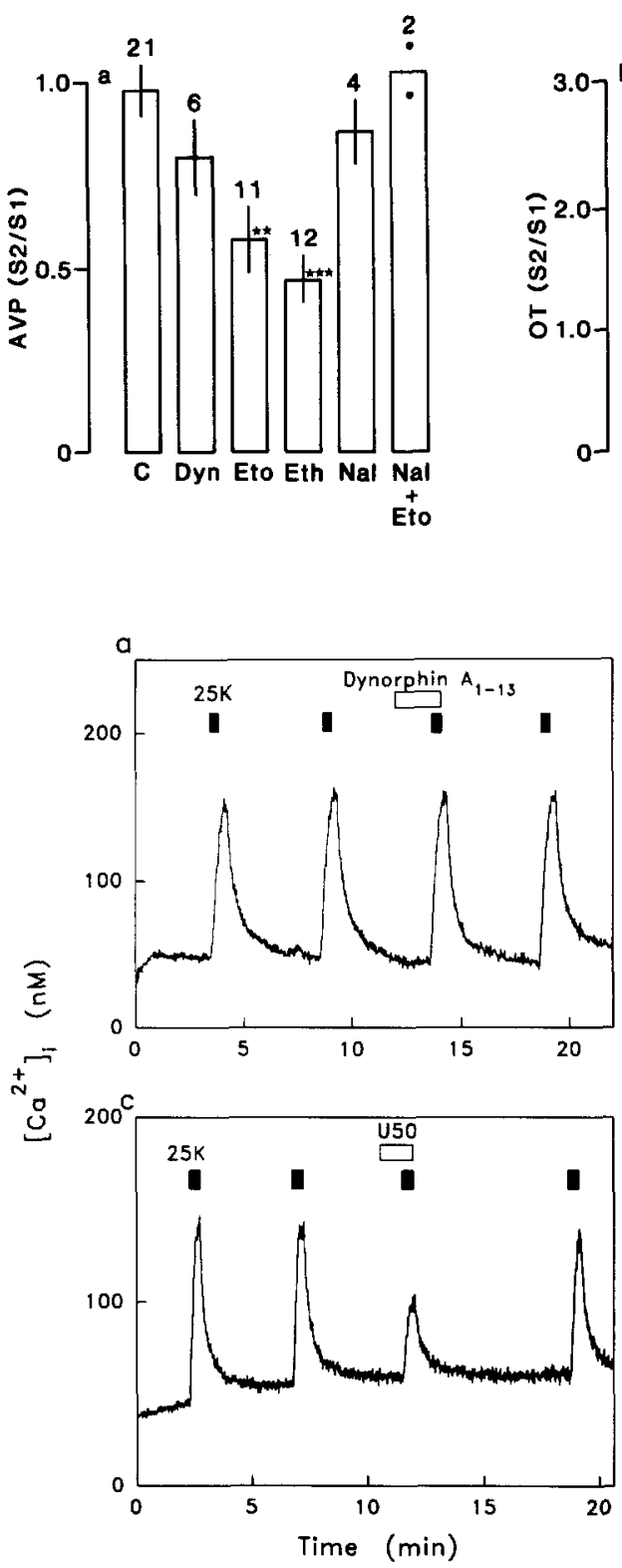
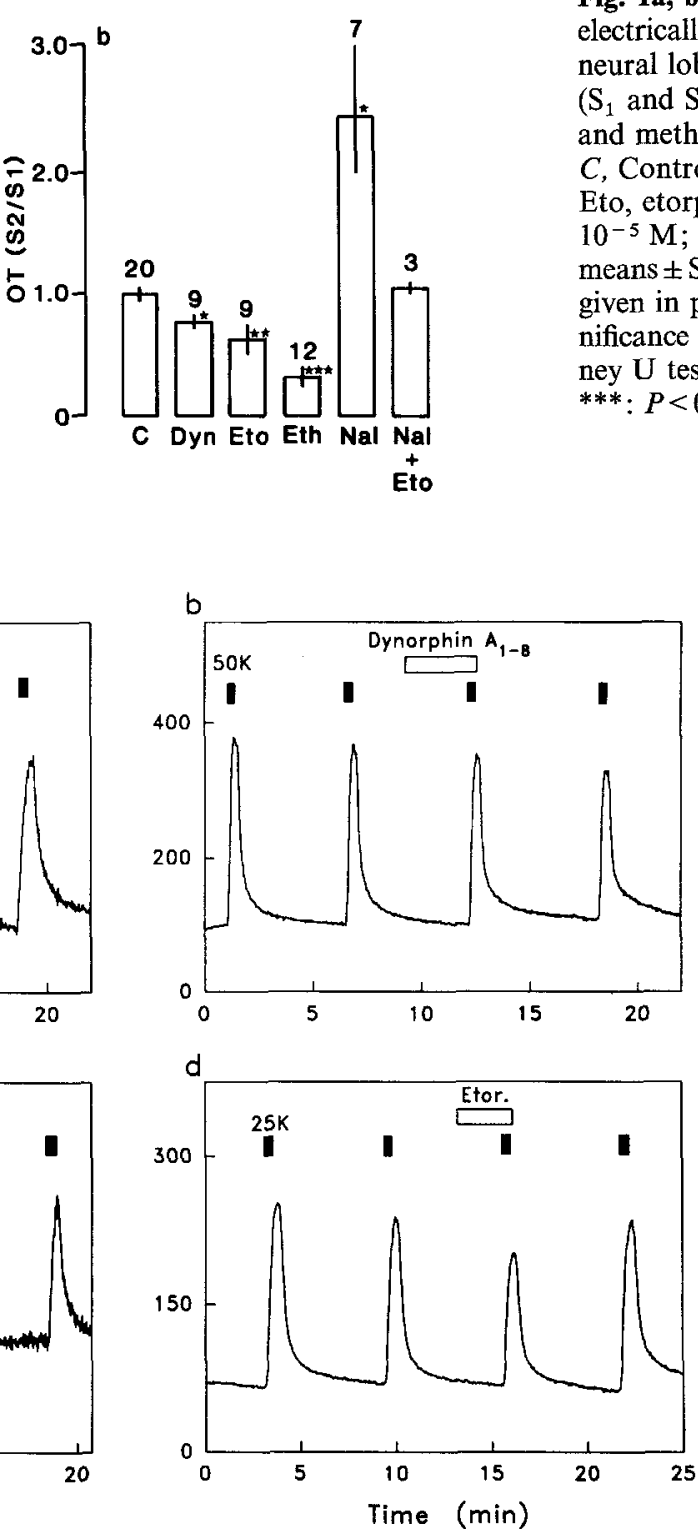

Fig. 1a, b. Effects of kappa-receptor agonists on electrically evoked hormone release from isolated neural lobes. Each neural lobe received two periods $\left(S_{1}\right.$ and $S_{2}$ ) of stimulation (4 bursts, see Materials and methods). a AVP release; b oxytocin release. $C$, Control; Dyn, dynorphin $\mathrm{A}_{(1-13)}\left(10^{-6} \mathrm{M}\right)$; Eto, etorphin $10^{-5} \mathrm{M}$; Eth, ethylketocyclazocide $10^{-5} \mathrm{M}$; Nal, naloxone $10^{-5} \mathrm{M}$. Data are means \pm SEM and the number of experiments are given in parantheses above the columns. The significance level is relative to controls (Mann-Whitney $U$ test) with *: $P<0.03$; **: $P<0.003$; $* * *: P<0.001$
Fig. 2a-d. Representative recordings showing the effect of opioid agonists on basal $\left[\mathrm{Ca}^{2+}\right]_{i}$ and $\mathrm{K}+$-evoked increase in $\left[\mathrm{Ca}^{2+}\right]_{i}$. Records show the effect of a dynorphin $A_{(1-13)}\left(10^{-6} \mathrm{M}\right)$, b dynorphin $\mathrm{A}_{(1-8)}\left(10^{-6} \mathrm{M}\right)$, c $\mathrm{U} 50488\left(\mathrm{U} 50,10^{-6} \mathrm{M}\right.$ ) and $\mathbf{d}$ etorphin (Etor, $10^{-5} \mathrm{M}$ ). Agonists were added prior and during a $\mathrm{K}^{+}$-induced $(25 \mathrm{mM}, \mathbf{a}, \mathbf{c}, \mathbf{d} ; 50 \mathrm{mM}, \mathbf{b})$ depolarization. Signal represents that recorded from groups of 3-6 isolated nerve terminals. Switching of solutions as indicated above traces or dynorphin $A_{(1-8)}$ at $10^{-6} \mathrm{M}$, when compared to control stimulation periods. The values for $\mathrm{S}_{2} / \mathrm{S}_{1}$ were $0.80 \pm 0.10(n=6)$ for dynorphin $\mathrm{A}_{(1-13)}$ and $0.99 \pm 0.09$ $(n=5)$ for dynorphin $\mathrm{A}_{(1-8)}$, respectively. In contrast, a $24 \%$ inhibition of OT secretion to dynorphin $A_{(1-13)}$ $\left(S_{2} / S_{1}=0.76 \pm 0.06, n=9\right)$ treatment was observed (Fig. 1b). Similarly, a slight, but significant decrease of OT release was observed with dynorphin $A_{(1-8)}\left(S_{2} /\right.$ $\mathrm{S}_{1}=0.80 \pm 0.04, n=5$ ). To examine if the lack of effect of the dynorphin on AVP secretion may have resulted from proteolytic degradation, similar experiments were performed in the presence of protease inhibitors. The results were however, not significantly different from those obtained in the absence of the inhibitors and, therefore, the results in the presence and absence of inhibitors have been pooled. Note that the amplitude of the secretory response were not significantly different in preparations in the presence or the absence of the inhibitors.
Selectivity of the dynorphin effect for the kappareceptor type was investigated by using two other opioid receptor agonists, etorphin and ethylketocyclazocine, which show less selectivity for this receptor type. Of importance, a significant reduction in the electrically evoked release of both AVP and OT at $10^{-5} \mathrm{M}$ from intact neural lobes (Fig. 1a, b) was observed. Lower concentrations, however, were without effect. Naloxone $\left(10^{-5} \mathrm{M}\right)$, a non-selective opiate receptor antagonist, was effective in antagonizing the inhibitory effects of etorphin $\left(10^{-5} \mathrm{M}\right)$ on the electrically induced secretion of both AVP and OT (Fig. 1). Naloxone alone was without effect on evoked AVP secretion (Fig. 1a), but potentiated electrically induced OT secretion (Fig. 1b). Furthermore, etorphin had no effect on the $\mathrm{K}^{+}$-evoked release of AVP release and OT from the isolated perfused nerve endings (not shown).

Additional experiments examined, in preparations of isolated nerve endings, the effects of dynorphin and a 


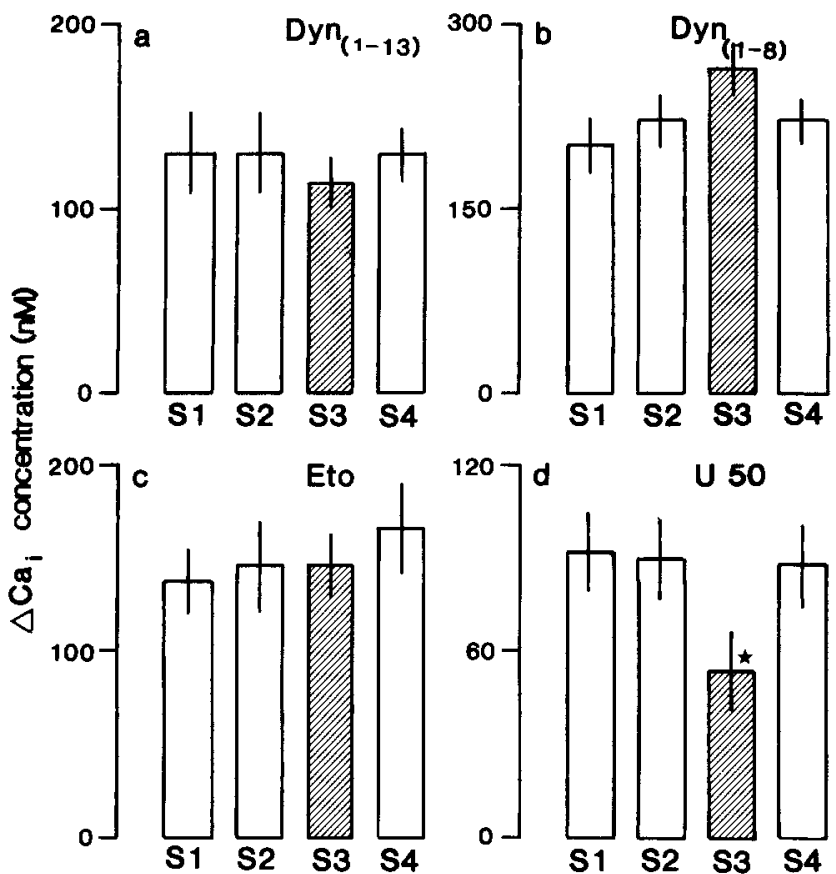

Fig. 3a-d. Averaged results comparing the effect of opioid agonists on the $\mathrm{K}^{+}$-evoked increase in $\left[\mathrm{Ca}^{2+}\right]$. Two control stimulations $\left(25 \mathrm{mM} \mathrm{K}^{+}, 45 \mathrm{~s}\right)$ preceded each test stimulation in the presence of a dynorphin $A_{(1-13)}\left(D Y N, 10^{-6} \mathrm{M}\right)$, b dynorphin $A_{(1-8)}(D Y N$, $10^{-6} \mathrm{M}$ ), c etorphin (ETO, 10 ${ }^{-5} \mathrm{M}$ ) and d U50 $488\left(\mathrm{U} 50,10^{-6} \mathrm{M}\right.$ ). The results represent the mean \pm SEM determined from at least three separate determinations. The significance level is relative to controls (Mann-Whitney U test) with ${ }^{*}: P<0.04$

stable opioid kappa-receptor agonist, U-50 488, on AVP and OT release. Secretion was evoked by depolarization of the nerve endings with saline containing $60 \mathrm{mM}$ potassium for a period of $10 \mathrm{~min}$. The ratios $\mathrm{S}_{2} / \mathrm{S}_{1}$ for the release of AVP and OT were for controls $0.59 \pm 0.07$ $(n=9)$ and $0.77 \pm 0.05(n=20)$, respectively (means \pm SEM). In the experiments in which U-50 $488\left(10^{-5} \mathrm{M}\right)$ was added during the second depolarization period, the values obtained were $0.59 \pm 0.07(n=11)$ and $0.68 \pm 0.07$ $(n=11)$, respectively, and were not significantly different from the controls. Using the $S_{2} / S_{1}$ paradigm we found that the secretory response to $25 \mathrm{mM} \mathrm{K}^{+}$was not modified, in contrast to the $\mathrm{Ca}^{2+}$ response, by $\mathrm{U}-50488$ $\left(10^{-6} \mathrm{M}\right)$ [Control, $0.93 \pm 0.04 \quad(n=5) ; \quad \mathrm{U}-50488$, $0.94 \pm 0.04(n=6)]$. Likewise, dynorphin was also found to have no effect on the release of AVP and OT from the isolated perfused nerve endings. Thus, not all the "selective" kappa-receptor agonists are equally effective in modulating the evoked release of AVP and OT.

\section{Effects of opioid agonists on $\left[\mathrm{Ca}^{2+}\right]_{i}$}

The effects of several opioid receptor agonists on resting and $\mathrm{K}^{+}$-evoked $(25 \mathrm{mM})\left[\mathrm{Ca}^{2+}\right]_{\mathrm{i}}$ was investigated in isolated nerve endings loaded with the $\mathrm{Ca}^{2+}$-sensitive, fluorescent probe fura-2. Figure 2 shows that dynorphin $\mathrm{A}_{(1-13)}$ and dynorphin $\mathrm{A}_{(1-8)}$ at $10^{-6} \mathrm{M}$ had no significant effect on either basal $\left[\mathrm{Ca}^{2+}\right]_{\mathrm{i}}$ or the $\mathrm{K}^{+}$-evoked increase in $\left[\mathrm{Ca}^{2+}\right]_{\mathrm{i}}$. In comparison, U-50 $488\left(10^{-6} \mathrm{M}\right)$ produced a small, but significant, decrease in the $\mathrm{K}^{+}$induced increase in $\left[\mathrm{Ca}^{2+}\right]_{\mathrm{i}}$ while basal $\left[\mathrm{Ca}^{2+}\right]_{\mathrm{i}}$ was not affected by this agonist. In each case, recovery was complete after washout of the drug, as judged by the response obtained during a fourth stimulation. The data are summarized in Fig. 3. Statistical analysis showed that among the agonists used, only U-50488 had a significant $(P<0.01)$ inhibitory effect on the increased calcium concentration triggered by an elevation of the external potassium concentration.

\section{Effects of opioid antagonists on AVP and OT release}

To address further the specificity of opioid actions, the effect of opioid antagonists on AVP and OT release were investigated in neural lobes stimulated electrically using the $S_{2} / S_{1}$ paradigm (see above). Diprenorphin $\left(10^{-5} \mathrm{M}\right)$ or MR $2266\left(10^{-6} \mathrm{M}\right)$, which are considered as selective antagonists (but see Smith et al. 1984) for kappa-receptors, decreased by a small ( 26 and $25 \%$ ) but significant extent the electrically evoked release of AVP and OT (Fig. 4a). However, potassium-induced hormone secretion from the neurohypophysis was not changed significantly by MR 2266 (Fig. 4b). In all cases, no significant effects of the antagonists were found on basal secretion of either AVP or OT (not illustrated).

\section{Effects of opioid antagonists on $\left[\mathrm{Ca}^{2+}\right]_{i}$}

Potential effects of opioid antagonists on $\left[\mathrm{Ca}^{2+}\right]_{\mathrm{i}}$ were investigated on isolated nerve endings tested with $25 \mathrm{mM}$
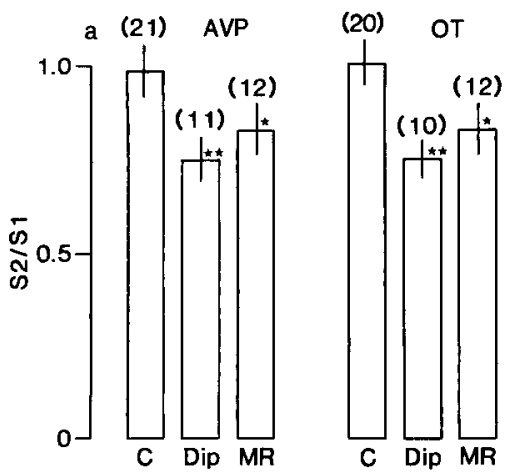
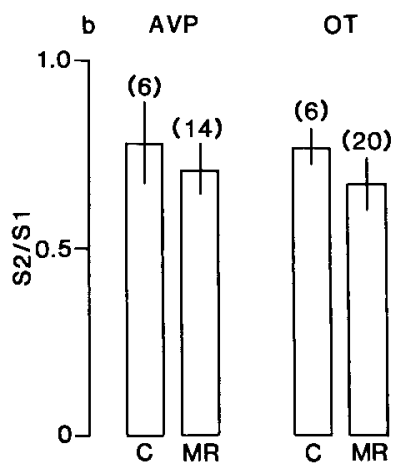

Fig. 4a, b. Effects of kappa-receptor antagonists on evoked hormone release from: a electrically stimulated ( 4 bursts, see Materials and methods) neural lobes and $\mathbf{b} 60 \mathrm{mM} \mathrm{K}{ }^{+}$-depolarized isolated nerve endings. $C$, Control; Dip, diprenorphin $10^{-5} \mathrm{M}$; MR $226610^{-6} \mathrm{M}$. Results are expressed as $\mathrm{S}_{1} / \mathrm{S}_{2}$ ratios. Data are given as means $\pm S E M$, with the number of experiments being above the columns. The significance level is relative to controls (MannWhitney $U$ test) with $*: P<0.03$; **: $P<0.01$. 

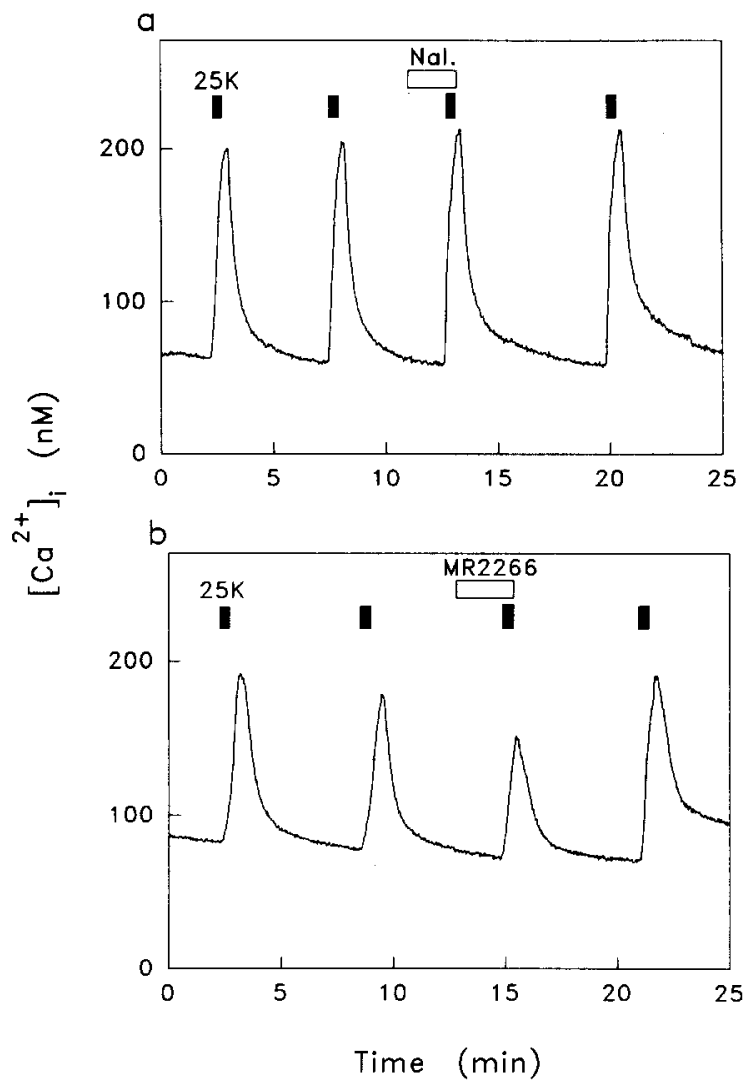

Fig. 5a, b. Representative recordings showing the effect of opioid antagonists on basal $\left[\mathrm{Ca}^{2+}\right]_{1}$ and $\mathrm{K}^{+}$-evoked increase in $\left[\mathrm{Ca}^{2+}\right]_{\text {. }}$. Records show effect of a naloxone (NAL, $10^{-5} \mathrm{M}$ ) and b MR 2266 (MR, $10^{-6} \mathrm{M}$ ) added prior to and during a $\mathrm{K}^{+}$-induced $(25 \mathrm{mM})$ depolarization. Signal recorded from groups of 3-6 nerve endings. Switching of solutions as indicated

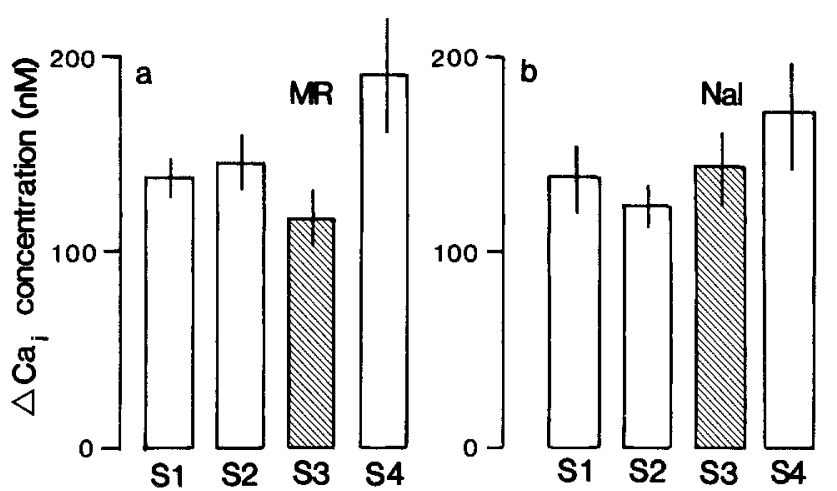

Fig. 6a, b. Averaged results comparing the effect of opioid antagonists on the $\mathrm{K}^{+}$-evoked increase in $\left[\mathrm{Ca}^{2+}\right]_{\mathrm{i}}$. Two control stimulations $\left(25 \mathrm{mM} \mathrm{K} \mathrm{K}^{+}, 45 \mathrm{~s}\right)$ preceded each test stimulation in the presence of a MR $2266\left(\mathrm{MR}, 10^{-6} \mathrm{M}\right)$ and b naloxone (NAL, $10^{-5} \mathrm{M}$ ). The results represent the mean \pm SEM determined from at least three separate determinations

potassium. Both naloxone $\left(10^{-5} \mathrm{M}\right)$ and $\mathrm{MR} 2266$ $\left(10^{-6} \mathrm{M}\right)$ were without significant effect on either basal $\left[\mathrm{Ca}^{2+}\right]_{\mathrm{i}}$ or the stimulated increase in $\left[\mathrm{Ca}^{2+}\right]_{\mathrm{i}}$ (Fig. 5). Figure 6 summarizes the data obtained with the different antagonists and demonstrates the lack of effects. Furthermore, in two other experiments diprenorphin also
Table 1. Effects of naloxone on the $\mathrm{K}^{+}$-induced release of AVP and OT from nerve endings isolated from control and dehydrated rats. Results are expressed as $\mathrm{S}_{2} / \mathrm{S}_{1}$ ratios, as described in the Materials and methods section. Rats were dehydrated for a period of 3 days. The nerve endings were depolarized with $60 \mathrm{mM}$ potassium for a 10 min period. Data are means $\pm S E M$ and the number of experiments are given in parentheses

\begin{tabular}{lll}
\hline & $\mathrm{VP} \mathrm{S}_{2} / \mathrm{S}_{1}$ & $\mathrm{OT} \mathrm{S}_{2} / \mathrm{S}_{1}$ \\
\hline $\begin{array}{l}\text { Normal rats } \\
\text { Control }\end{array}$ & $0.88 \pm 0.09(12)$ & $0.91 \pm 0.05(7)$ \\
Naloxone $10^{-5} \mathrm{M}$ & $0.74 \pm 0.11(14)$ & $0.97 \pm 0.10(14)$ \\
Dehydrated rats & & \\
Control & $0.86 \pm 0.08(12)$ & $0.91 \pm 0.04(24)$ \\
Naloxone $10^{-5} \mathrm{M}$ & $0.80 \pm 0.11(14)$ & $0.97 \pm 0.13(12)$ \\
\hline
\end{tabular}

failed to modify the calcium response to the $\mathrm{K}^{+}$-induced depolarization. Thus, none of the opioid antagonists used in this study had an effect on $\left[\mathrm{Ca}^{2+}\right]_{i}$ associated with depolarization of the nerve terminals.

\section{Effects of physiological state on responsiveness to opioids}

The effect of opiate receptor antagonists on hormone release from neural lobes obtained from dehydrated rats was studied. Under these conditions, the electrical activity of the magnocellular neurons is greatly enhanced (for review see Poulain and Wakerley 1982), leading to increased secretion. The rats were dehydrated for 3 days, and the isolated neurohypophyses were stimulated with $60 \mathrm{mM}$ potassium using the $S_{2} / S_{1}$ paradigm. The mean control values for AVP and OT release were, respectively, $0.94 \pm 0.14(n=10)$ and $0.91 \pm 0.04(n=24)$. In the presence of the opiate receptor antagonist MR 2266 $\left(10^{-6} \mathrm{M}\right)$, the mean values were $1.02 \pm 0.15(n=18)$ and $0.94 \pm 0.07(n=14)$ for AVP and OT, respectively. In comparison, naloxone $\left(10^{-5} \mathrm{M}\right)$, was without effect on both AVP and OT secretion triggered by depolarization with elevated $\mathrm{K}^{+}$(Table 1).

\section{Discussion}

The presence of opiate receptors in the neural lobe was first described more than a decade ago (Simantov and Snyder 1977), but their nature and precise localization within the tissue have been difficult to analyze as judged by the contradictory results obtained from different laboratories. Opiate receptors were initially believed to be localized on the pituicytes (Lightman et al. 1983; Bunn et al. 1985), but later reports described their presence also on neurosecretory nerve terminals (Herkenham et al. 1986; Pesce et al. 1987; Falke and Martin 1988). Quantitative autoradiography of tritiated ligand-binding showed that the $\mu$ - and $\delta$-like receptors were virtually absent in the neural lobe and that only the presence of kappa-opioid receptors could be demonstrated (Bunn et 
al. 1985; Herkenham et al. 1986; Castanas et al. 1986; Gersterberger and Barden 1986; Falke and Martin 1988). Recently, this analysis has been extended with similar findings to preparations of isolated neurohypophysial nerve terminals (Pesce et al. 1987; Falke and Martin 1988). Yet $\left[\mathrm{H}^{3}\right]$ ethylketocyclazocine has been shown to exhibit high-affinity binding with complex isotherms consistent with the presence of multiple classes of binding sites (Gertsberger and Barden 1986; Pesce et al. 1987). In addition, $U-50488$ or dynorphin $A_{(1-8)}$, a naturally occurring kappa-ligand, only slowly and incompletely displaces the radiolabeled antagonist diprenorphin (Gertsberger and Barden 1986; Falke and Martin 1988). Finally, in a very careful analysis of the distribution of receptors in the neural lobe, Falke and Martin (1988) found the opioid binding sites were preferentially localized on neurosecretory terminals containing oxytocin. Thus taken together autoradiographic and binding studies suggest that on the neurohypophysial nerve endings kappa-receptors represent the largest population of opioid receptors, but the presence of $\mu$ - or $\delta$-type receptors cannot be entirely excluded.

Both the localization of endogenous dynorphin in the nerve endings and opiate receptors in the neural lobe would suggest that the opioids could play a role in the control of the release of neurohypophysial hormones. However, the results obtained by different groups are far from convincing. Interesting examples are the effects of the Leu-enkephalin analogue DADLE and of $\beta$-endorphin on the release of hormone from the neural lobe. It was first demonstrated that both molecules have an inhibitory effect on the electrically evoked AVP release (Iversen et al. 1980; Lightman et al. 1982) and that an enkephalin analogue decreased the secretion of oxytocin. However, others have been unable to find a significant effect of these molecules on hormone release (Bicknell and Leng 1982; Denker et al. 1982; Lutz-Bucher et al. 1982; Pitzel and Konig 1984; Nordmann et al. 1986). Similarly, contradictory data have been obtained with other opioid molecules (for references, see Table 2 in Nordmann et al. 1986).

The present study attempted to explain the different and contradictory results obtained by different groups on the modulation of neurohypophysial hormone release by opioid molecules. In a recent study (Zhao et al. 1988a), it had been shown that $\mathrm{K}^{+}$-induced secretion of both AVP and OT from isolated neurohypophysial nerve terminals was inhibited by two specific kappa-agonists, namely, U-50 488 and dynorphin $A_{(1-13)}$ (for specificity see Gairin et al. 1985; Von Voigtlander et al. 1983). This effect was prevented by the non-specific antagonist naloxone (Zhao et al. 1988a). Similarly, U-50 488 was shown to inhibit, by about $30 \%$, the electrically induced AVP and OT release, and this effect was prevented by a tenfold molar excess of naloxone (Zhao et al. 1988b). However, DAGO, which is believed to be specific for the $\mu$-type receptor, also affected, although to a smaller extent, the release of AVP and possibly that of OT. It has to be pointed out that earlier reports failed to observe an inhibitory effect of kappa-agonists on secretion (Bicknell et al. 1985). The results of the present study failed to demonstrate an effect of $\mathrm{U}-50488$ on the $\mathrm{K}^{+}$-evoked AVP and OT release from isolated nerve endings, although a decrease in evoked $\left[\mathrm{Ca}^{2+}\right]_{\mathrm{i}}$ occurred. On the other hand, dynorphin $\mathrm{A}_{(1-13)}$, another kappa receptor agonist, inhibited the electrically-induced release of OT but was without effect on AVP secretion (Fig. 1) or on $\mathrm{K}^{+}$-evoked changes in $\left[\mathrm{Ca}^{2+}\right]_{\mathrm{i}}$ in isolated nerve endings (Figs. 2, 3). It should be pointed out that effects of opiates on electrically induced release on OT (but not AVP) were only observed when the neural lobes were stimulated at low frequency $(4 \mathrm{~Hz})$ (Bondy et al. 1988). However, as the magnocellular neurons do not generally fire at such frequencies (see for details Poulain and Wakerley, 1982) these results might have no relevance for studies in vivo. The very significant inhibitory effects of etorphin and ethylketocylazocin on secretion (Fig. 1) are of interest because these molecules show less specificity among the opioid receptors (Wood 1984). However, account should be taken of the relatively high concentrations used in these experiments when interpreting the physiological role of opiates in the stimulus-secretion mechanism, at the level of the neurohypophysial nerve endings. It suggests the results presented here, and in other studies, for the opiate effects in this tissue should be assessed with caution.

The lack of effect of the two antagonists, diprenorphin and MR 2266, on AVP and OT release and on evoked changes in $\left[\mathrm{Ca}^{2+}\right]_{\mathrm{i}}$ is in contrast to the results of Bicknell et al. (1985), who observed potentiation of OT and AVP release by MR 2266. Our results are, however, in agreement with the observation made by the same authors that, at high concentrations, the antagonists show a strong agonist-like effect. Finally our results confirm that at high doses $\left(10^{-5} \mathrm{M}\right)$ naloxone - which, at lower doses, had no effect on the secretory mechanism in normal rats (Nordmann et al. 1986) - potentiates the electrically induced OT release and can overcome the inhibitory effect of agonists such as etorphin. Naloxone had no effect, however, on perfused isolated nerve endings stimulated with potassium. This is in agreement with the results of Zhao et al. (1988a) who found that the release of OT from isolated nerve terminals was not affected by naloxone.

Although the present data brings into doubt the specificity or identity of the receptors with which opiates could act on the secretion of AVP and OT, it clearly demonstrates that the calcium increase in the cytoplasm, which follows the depolarization of the isolated nerve terminals, is not systematically affected by the opioid agonists. It has been known for some time that activation of kappa receptors can reduce the calcium current in neurons (North and Williams 1985; MacDonald and Wertz 1986; North 1986), and this should diminish the evoked transmitter release. However, the present data show that the spatially averaged calcium increase in the depolarized isolated neurohypophysial nerve endings is not affected by dynorphin $A_{(1-13)}$ or dynorphin $A_{(1-8)}$ acting on opiate receptors. The inhibitory effect of U-50 488 on the potassium-induced calcium increase corresponds to a small change of $\left[\mathrm{Ca}^{2+}\right]_{\mathrm{i}}$ (ca. $65 \mathrm{nM}$ ). Thus, if opioid molecules can modulate the secretion of AVP and OT, 
they may act at a step downstream from the activation of the calcium channels. As opiate molecules do not act on permeabilized nerve endings (unpublished observations), i.e. nerve endings in which the depolarization step is bypassed (Cazalis et al. 1987b), the remaining step at which opiate molecules could act would be at or close to the external site of the plasma membrane at which exocytosis occurs.

Most of the experiments described in this paper have been performed using paradigms similar to those used by other researchers but who obtained results different from ours. One possibility could be that animals, even originally from the same strain, can differ considerably in the way they respond to opioid molecules. Another alternative would be to consider the physiological state of the animal. It is our contention that the modulation of neurohypophysial hormone secretion by opioid molecules remains unresolved and awaits the development of highly specific opioid agonists and antagonists and the precise characterization of the opioid receptors involved.

Acknowledgements. We thank John Bicknell (Babraham, England) for the gift of antisera for AVP and OT and for naloxone and U-50 488, Pierre Giraud (Marseille, France) for etorphin, ethylketocyclazocine and diprenorphin and Madame Kempf for MR 2266. The work was supported by CNRS (JJN) and NSF, (911092) Rackham grants (ELS).

\section{References}

Al Zein M, Lutz-Bucher B, Koch B (1984) Modulation by Leuenkephalin of peptide release from perfused neurointermediate pituitary. Neuroendocrinology 39:292-296

Bicknell RJ, Leng G (1982) Endogenous opiates regulate oxytocin but not vasopressin and secretion from the neurohypophysis. Nature 298:161-162

Bicknell RJ, Chapman C, Leng G (1985) Effects of opioid agonists and antagonists on oxytocin and vasopressin release in vitro. Neuroendocrinology $41: 142-148$

Bondy CA, Gainer H, Russell JT (1988) Dynorphin A inhibits and naloxone increases the electrically stimulated release of oxytocin but not vasopressin from the terminals of the neural lobe. Endocrinology 122:1321-1327

Bunn SJ, Hanley MR, Wilkin GP (1985) Evidence for a kappaopioid receceptor on pituitary astrocytes: an autoradiographic study. Neurosci Lett 55:317-323

Castanas E, Blanc D, Bourhim N, Cupo A, Cantau P, Giraud P (1986) Reassessment of opioid binding sites in the rat brain. Neuropeptides 7:369-380

Cazalis M, Dayanithi G, Nordmann JJ (1985) The role of patterned burst and interburst interval on the excitation-coupling mechanism in the isolated rat neural lobe. J. Physiol (Lond) 369:45-60

Cazalis M, Dayanithi G, Nordmann JJ (1987a) Hormone release from isolated nerve endings of the rat neurohypohysis. J Physiol (Lond) 390:55-70

Cazalis M, Dayanithi G, Nordmann JJ (1987b) Requirements of hormone release from pemeabilized nerve endings isolated from the rat neurohypophysis. J Physiol (Lond) 390:71-91

Denker Christensen JD, Fjallan B (1982) Lack of effect of opiates on release of vasopressin from isolated rat neurophypophysis. Acta Pharmacol Toxicol 50:113-116

Dreifuss JJ, Grau JD, Bianchi RE (1971) Antagonism between Ca and $\mathrm{Na}$ ions at neurohypophyseal nerve terminals. Experientia 27: 1295-1296

Falke N, Martin R (1988) Opiate binding differentially associated with oxytocin and vasopressin nerve endings from porcine neurohypophyses. Exp Brain Res 70:145-154
Gairin JE, Gouarderes C, Mazarguil H, Alvinerie P, Gross J (1985) $\left(\mathrm{D}-\mathrm{Pro}^{10}\right)$ dynorphin - (1-11) is a highly potent and selective ligand for K-opioid receptors. Eur J Pharmacol 106:457-458

Gerstberger R, Barden N (1986) Dynorphin 1-8 binds to opiate kappa receptors in the neurohypophysis. Neuroendocrinology 42:376-382

Grynkiewicz G, Poenic M, Tsien RW (1985) A new generation of $\mathrm{Ca}^{2+}$ indicators with greatly improved fluorescence properties. J Biol Chem 260:3440-3450

Herkenham M, Rice KC, Jacobson AE, Rothman RB (1986) Opiate receptors in rat pituitary are confined to the neural lobe and are exclusively kapa. Brain Res 382:365-371

Iversen LL, Iversen SD, Bloom FE (1980) Opiate receptors influence vasopressin release from nerve terminals in rat neurohypophysis. Nature 284:350-351

Knepel W, Meyer DK (1983) The effect of naloxone on vasopressin release from rat neurohypophysis incubated in vitro. J Physiol (Lond) 341:507-515

Lightman SL, Iversen LL, Forsling ML (1982) Dopamine and $\left(\mathrm{D}-\mathrm{Ala}^{2}, \mathrm{D}-\mathrm{Leu}^{5}\right)$ enkephalin inhibit the electrically stimulated neurohypophyseal release of vasopressin in vitro: evidence for calcium-dependent opiate action. J Neurosci 2:78-81

Lightman SL, Ninkovic M, Hunt SP, Iversen LL (1983) Evidence for opiate receptors on pituicytes. Nature 305:235-237

Lutz-Bucher B, Koch B, Al Zein M (1982) Direct stimultory effect of angiotensin II on neurohormone release from posterior pituitary and modulation by opiates. Neuroendocrinol Lett 4:103-107

MacDonald RL, Wertz MA (1986) Dynorphin A decreases voltagedependent calcium conductance of mouse dorsal root ganglion neurons. J Physiol (Lond ) 377:237-249

Nordmann JJ (1976) Evidence for calcium inactivation during hormone release in the rat neurohypophysis. J Exp Biol. 65:669-683

Nordmann JJ, Dayanithi G, Cazalis M (1986) Do opioid peptides modulate, at the level of the nerve endings, the release of neurohypophysial hormones? Exp Brain Res 61:560-566

North RA (1986) Opioid receptor types and membrane ion channels. TINS 9:114-117

North RA, Williams JT (1985) On the potassium conductance increased by opioids in rat locus coeruleus neurones. J Physiol (Lond) 384:265-276

Pitzel L, Konig A (1984) Lack of response in the release of oxytocin and vasopressin from isolated neurohypophyses to dopamine, Met-enkephalin and Leu-enkephalin. Exp Brain Res $56: 221-226$

Pesce G, Lang MA, Russel JT, Rodbard D, Gainer H (1987) Characterization of $\mathrm{K}$ opioid receptors in neurosecretosomes from bovine posterior pituitary. J Neurochem 49:421-427

Poulain DA, Wakerley JB (1982) Electrophysiology of hypothalamic magnocellular neurons secreting oxytocin and vasopressin. Neuroscience 7:773-808

Simantov R, Snyder SH (1977) Opiate receptor binding in the pituitary gland. Brain Res $124 ; 178-184$

Smith CB, Bennet-Kelly L, Woods JH (1984) Comparison of "selective" opiate receptor antagonists on the isolated mouse vas deferens. Neuropeptides 5:161-164

Stuenkel EL (1990) Effects of membrane depolarization on intracellular calcium in single nerve terminals. Brain Res 529:96-101

Von Voigtlander PF, Lahti RA, Ludens JH (1983) U-50 488: a selective and structurally novel non-mu (kappa) opioid agonist. J Pharmacol Exp Ther 224:7-12

Wood PL (1984) K-agonist analgesics: evidence for $\mu_{2}$ and $\delta$ opioid receptor antagonism. Drug Dev Res 4:429-435

Zhao BG, Chapman C, Biknell RJ (1988a) Functional k-opioid receptors on oxytocin and vasopressin nerve terminals isolated from the rat neurohypophysis. Brain Res 462:62-66

Zhao BG, Chapman C, Bicknell RJ (1988b) Opioid-noradrenergic interactions in the neurohypophysis. Neuroendocrinology $48: 16-24$ 